\title{
Stress responsiveness affects dominant-subordinate relationships in rainbow trout
}

T. G. Pottinger* and T. R. Carrick

NERC Centre for Ecology and Hydrology, Windermere Laboratory,

The Ferry House, Far Sawrey, Ambleside,

Cumbria LA22 OLP, United Kingdom

Running head: Stress responsiveness and dominance in trout

*Corresponding author:

Email: tgp@ceh.ac.uk;

Tel.: +44 (0)15394-42468;

Fax: +44 (0)15394-46914 
(Abstract) The magnitude by which plasma cortisol levels increase following exposure to a stressor is a heritable trait in rainbow trout. The relative growth in coculture of F1 lines selected for high-responsiveness (HR) and low-responsiveness (LR) to a confinement stressor suggested that behavioral characteristics related to food acquisition, aggression or competitive ability might differ between the two lines. This hypothesis was tested using the F2 generation of the selected lines. The F2 lines clearly exhibited the characteristics of the F1 parents, displaying significantly divergent plasma cortisol responses to a $1 \mathrm{~h}$ confinement stressor and a high heritability for the trait. Behavioral differences between the lines were assessed by observing the outcome of staged fights for dominance in size-matched pairs of HR and LR fish. The identification of dominant and subordinate fish within each pair on the basis of their behavior was supported by the levels of blood cortisol in the fish attributed to each group (dominant $<$ subordinate). Fish from the LR line were identified as dominant in significantly more trials than were HR individuals. The results suggest that behavioral attributes that affect the outcome of rank-order fights are closely linked to the magnitude of the plasma cortisol response to stress in rainbow trout. Whether the link is causal or circumstantial is not yet evident.

Key words: stress, dominance, cortisol, behavior, rainbow trout, aggression, Oncorhynchus mykiss 


\section{INTRODUCTION}

The detrimental effects for salmonid fish of prolonged elevation of blood cortisol levels are well-established (Barton, 1997) but the functional significance of interindividual differences in the magnitude of the cortisol response to stressors in salmonid fish, and the extent to which other elements of the adaptive stress response are functionally associated with this trait, is yet to be fully established (Pottinger and Carrick, 1999a). In rainbow trout (Oncorhynchus mykiss Walbaum) the magnitude to which plasma cortisol is elevated following exposure to a stressor is a stable trait (Pottinger, Pickering and Hurley, 1992) with a moderate to high degree of heritability $\left(h^{2}=0.4-0.6 ;\right.$ Fevolden, Røed, Fjalestad and Stien, 1999; Pottinger and Carrick, 1999b). These attributes have facilitated the selective breeding of two lines of trout (high-responding - HR; low-responding - LR) with divergent cortisol responsiveness to a standardized confinement stressor (Pottinger and Carrick, 1999b).

During studies on the F1 generation of the selected lines it was observed that LR and HR fish displayed similar growth rates when maintained in monoculture, but fish from the LR line grew larger in co-culture than did HR fish (T. G. Pottinger and T. R. Carrick, unpublished data). This disparity suggested that the difference in performance between the lines might be linked to differences in aggressiveness or competitiveness. It is well established that the most aggressive or competitive individuals within a population of salmonid fish become socially dominant and compete most successfully for food (Adams, Huntingford, Turnbull and Beattie, 1998). Agonistic interaction and resultant social dominance/subordination is one of the best-documented aspects of salmonid behavior and dominance represents an 
element within the behavioral repertoire of salmonid fish, which is of demonstrable significance to individual performance (Adams et al., 1998; Metcalfe, 1989, 1998; Petersson, Jarvi, Olsen, Mayer and Hedenskog, 1999; Ryer and Olla, 1996). We therefore investigated whether differences in aggressiveness or competitiveness might contribute to the different growth patterns observed in the two lines. The large size of the F1 fish, and relatively small numbers available, precluded their use and the investigation was continued with the newly established F2 generation.

The method adopted to investigate the relative tendency towards dominant or subordinate status of the HR and LR lines has been used successfully by others to initiate and investigate dominant-subordinate relationships in rainbow trout. Juvenile rainbow trout, in common with other predominantly stream-resident salmonids are intensely territorial animals (Hutchison and Iwata, 1997; Keenleyside and Yamamoto, 1962; Taylor, 1990) and when introduced simultaneously into an arena will engage in agonistic activity that results in the establishment of a dominant-subordinate relationship (Jönsson, Johnsson and Björnsson, 1998; Øverli et al., 1999; Winberg and Lepage, 1998). Behavioral differences between the F2 lines were investigated by observing the outcome of fights for social dominance between HR and LR by pairing fish from the F2 HR and LR lines in a series of dyadic encounters. The outcome of each contest, in terms of the manifestation of dominant and subordinate behaviors, was evaluated by scoring selected behaviors, and blood cortisol levels were determined for each fish after pairing in order to provide confirmation of social status. 


\section{MATERIALS AND METHODS}

\section{Selection of F1 fish}

During previous studies (Pottinger and Carrick, 1999b), the two F1 families of rainbow trout that displayed the most divergent mean plasma cortisol response to a 3 h period of confinement were identified. During June 199925 fish were randomly netted in batches of five from each of two holding tanks (1000 liters capacity, circular glass fiber, supplied with a constant flow of lake water at $301 \mathrm{~min}^{-1}$ at ambient temperature) containing LR fish (mean weight $\forall$ SEM, $859 \forall 19 \mathrm{~g}, \mathrm{n}=50$ ) and transferred to anesthetic (2-phenoxyethanol, 1:2000). Each fish was weighed, measured and a PIT (Passive Integrated Transponder, Fish Eagle Co.) tag was implanted in the dorsal musculature. The fish were then transferred to two new holding tanks. The same procedure was repeated with HR fish (mean weight $\forall$ SEM, $639 \forall 14 \mathrm{~g}, \mathrm{n}=50)$. On three occasions, during July, August and November 1999, fish were transferred from the holding tanks, in groups of five, to confinement tanks (50 1, rectangular polypropylene, supplied with lake water $151 \mathrm{~min}^{-1}$ ). After $2-3$ hours from the initial disturbance fish from each confinement tank were transferred to anesthetic (the precise time elapsed from the initial disturbance was recorded for each fish). The PIT tag number was recorded and the fish were weighed, measured and a blood sample was collected from the Cuverian sinus into a $2.0 \mathrm{ml}$ heparinized syringe. During the final confinement test in November a note was made of the sex of each fish, which was readily identifiable at this time due to the pronounced sexual dimorphism exhibited by salmonid fish. The blood was kept on ice until the completion of sampling when it was spun down $\left(3000 \mathrm{~g}\right.$ at $4^{\circ} \mathrm{C}$ for 10 mins $)$. Separated plasma was transferred to a capped polypropylene tube and stored frozen (- 
$20^{\circ} \mathrm{C}$ ) until required for assay. Plasma cortisol levels were determined by radioimmunoassay.

The mean plasma cortisol response to confinement over the three episodes of confinement for each fish was ranked. The fifteen male and female fish with the lowest mean responses to confinement were identified from the LR group while from the HR fish the fifteen individuals of each sex with the highest mean response to confinement were identified. These individuals were maintained in same-sex groups. During January and February 2000 gametes from single HR and LR females were fertilized with milt from single males of the corresponding selection group to generate a series of full-sib families. A total of eleven LR and eleven HR families were generated. In addition, three unselected (US) families were produced using pooled gamete matings of fish from the random-bred line. Eggs were incubated in meshbased egg trays within incubator troughs and after hatch the alevins were transferred to covered stainless steel mesh baskets placed in the center of outdoor holding tanks, one family/tank. At swim-up, water levels within the holding tanks were increased and the fry were able to leave the baskets and enter the holding tank proper. Exogenous feeding was initiated at swim-up with fry food (Trouw 00, 01, 02, 03) at the manufacturers recommended rate, with crumb size increasing with age.

\section{The effects of confinement on plasma cortisol levels in the F2 families}

During September 2000 the effects of a confinement stressor on plasma cortisol levels in the F2 progeny of the selected parents was evaluated. At the time of confinement the overall mean weight of the fish was $22.9 \pm 0.6 \mathrm{~g}( \pm \mathrm{SEM}, \mathrm{n}=250)$ and they were $\sim 9$ months old. On Day 1, ten fish from each of five HR and five LR families were 
netted from their holding tanks ( 500 fish family ${ }^{-1}$; holding density $\left.\sim 10 \mathrm{~g} \mathrm{l}^{-1}\right)$ and transferred to stainless steel baskets suspended in confinement tanks (holding density $\left.\sim 80 \mathrm{~g} \mathrm{l}^{-1}\right)$ supplied with a constant flow of lake water $\left(15 \mathrm{l} \mathrm{min}^{-1}\right)$. The fish were transferred in groups at $20 \mathrm{~min}$ intervals to allow for subsequent delays incurred during the sampling procedure. Precisely $1 \mathrm{~h}$ after the initial disturbance all ten fish from the first confinement tank were netted and anaesthetized. Each fish was killed by a blow to the head and weighed and measured. A blood sample was collected into a heparinized glass micropipette after severing the caudal peduncle. Blood was transferred to a capped tube on ice before being spun down and frozen as described above. On Day 2, this procedure was repeated with a further five HR and five LR families. On Day 3, the remaining HR and LR families were sampled, together with the unselected random-bred families. Plasma cortisol levels were determined for each sample by radioimmunoassay.

Evaluation of the tendency towards dominance or submissiveness among F2 HR and LR fish

During September and October 2000 dyadic contests were performed following broadly the protocol of Øverli, Harris and Winberg (1999). On Day 1, twelve sizematched (by fork length) pairs of HR and LR fish (overall mean \pm SEM: HR: $11.6 \pm$ $0.18 \mathrm{~cm}$; LR: $11.6 \pm 0.19 \mathrm{~cm}$; mean \% difference between paired individuals: $0.29 \pm$ $0.33 \%, \mathrm{n}=47$ ), approximately one from each family, were transferred from their holding tanks to twelve glass aquaria (total water volume 63 1) supplied with lake water at the same temperature as that in the holding tanks $\left(1.51 \mathrm{~min}^{-1}\right)$. While anaesthetized for weighing and measuring one fish in each pair was marked on the anterior ventral surface with aqueous alcian blue delivered by a Panjet needleless 
injector (Wright Dental Co.). Half of the HR fish were marked and paired with unmarked LR fish and half of the LR fish were marked and paired with unmarked HR fish in each run. Each aquarium was divided into two compartments by a removable black partition and lined on three sides with black plastic. A plastic mesh cover prevented fish from jumping into the adjacent compartment while allowing the insertion of food. One fish from each pair was introduced into the compartment on either side of the partition. Overhead fluorescent tubes provided illumination in accordance with the natural daylength at the time of the experiments. Fish were offered food (5 crumbs, Trouw Fry 18) twice each day after being transferred to the aquaria. On the day on which behavioral observations were made, the food was offered at the start of each 5 minute observation period. The response of the fish to the food was recorded for each fish on each occasion. On Day 5 the central separating partition was removed from each tank. Three hours after removal of the partition each pair of fish was observed for two 5 minute periods, separated by 2 h. Two observers were each responsible for one of every pair of observation periods. Observations were made from behind a black plastic sheet with slits cut for viewing. During this period the behaviors manifested by the fish were assigned points such that the dominant fish accrued the highest number of points. The criteria employed to discriminate between the dominant and subordinate fish are among those that characterise dominance during agonistic encounters in salmonid fish (Keenleyside and Yamamoto, 1962; Øverli et al., 1999). The behaviors scored were: position of the fish within the tank (bottom, 1; mid-water, 2), their locomotory activity (none, 1; moderate, 2; extensive, 3), the presence (but not the frequency) of any overt agonistic behavior (none, 1; chasing, 2; chasing and biting, 3), and whether food was accepted (no, 1; second, 2; first, 3). Observations were made "blind" with regard to the identity of the fish. After 
completion of the observation period, each pair of fish was netted from the aquarium into anesthetic, killed by a blow to the head, and weighed and measured. A blood sample was collected from each fish into a heparinized glass micropipette tube after severing the caudal peduncle. Blood was processed as described above and stored frozen until being assayed for cortisol. A total of 49 pairs were set up over a four week period of which results were obtained for 47 (two mortalities occurred). To evaluate the degree to which fish transferred to the test aquaria had acclimated to the novel environment a group of twelve HR and twelve LR fish were transferred from holding tanks to the partitioned test aquaria, and held under identical conditions to the fish used in the behavioral trials. On Day 5 these fish were netted, anaesthetized and blood sampled without removing the partitions. Plasma cortisol levels were determined for each fish.

\section{Cortisol radioimmunoassay}

Plasma samples were extracted by vortex mixing with ethyl acetate (1:5; plasma:ethyl acetate). After centrifugation an aliquot of the extract $(20-150 \mu \mathrm{l})$ was transferred to $3.5 \mathrm{ml}$ polypropylene assay tubes. A standard curve was constructed by adding to a series of assay tubes, in duplicate, aliquots of ethyl acetate containing between 12.5 and 800 pg of inert cortisol (Sigma Aldrich). Blank tubes received ethyl acetate alone. A $50 \mu \mathrm{l}$ aliquot of ethyl acetate containing $20,000 \mathrm{dpm}$ of $\left[1,2,6,7-{ }^{3} \mathrm{H}\right]$ cortisol (Amersham Pharmacia Biotech; $60 \mathrm{Ci} \mathrm{mmol}{ }^{-1}$ ) was added to all the tubes and the solvent was evaporated under a vacuum. A $200 \mu \mathrm{l}$ aliquot of anti-cortisol antibody (IgG-F-2; IgG Corporation; 1:600) in phosphate buffered saline (PBS; Sigma) containing bovine serum albumin (RIA grade; Sigma; $0.1 \%$ ) was added to each tube (except two non-specific binding tubes which contained ${ }^{3} \mathrm{H}$-cortisol only) and the 
tubes were incubated overnight at $4^{\circ} \mathrm{C}$. After incubation, racks containing the assay tubes were placed on ice and a $100 \mu \mathrm{l}$ aliquot of chilled, stirred, dextran-coated charcoal in PBS (1.0 \% activated charcoal; $0.2 \%$ dextran) was added to each tube. After vortex mixing, the tubes were incubated on ice for 5 mins before being spun (3000g at $4^{\circ} \mathrm{C}$ for $10 \mathrm{mins}$ ). A $200 \mu \mathrm{l}$ aliquot of the supernatant was added to $4.5 \mathrm{ml}$ of scintillant (Ecoscint A; National Diagnostics) in a vial, mixed by inversion, and counted under standard $3 \mathrm{H}$ conditions. Cortisol concentrations in the unknown samples were calculated from the equation of a 3-parameter hyperbolic function fitted to a plot of the percentage of ${ }^{3} \mathrm{H}$-cortisol bound against pg of inert cortisol (Sigmaplot; SPSS Science). Sensitivity (minimal detection limit) of the assay was $0.3 \mathrm{ng} \mathrm{ml}^{-1}$. The inter-assay coefficients of variation for a low $\left(5 \mathrm{ng} \mathrm{ml}^{-1}\right)$ and high $\left(53 \mathrm{ng} \mathrm{ml}^{-1}\right)$ plasma sample were $8.4 \%$ and $8.1 \%(n=8)$ and the corresponding intra-assay coefficients of variation were $5.5 \%$ and $5.1 \%(n=8)$. Cross-reactivity of the antibody with cortisone, the most significant potential competitor in rainbow trout plasma, was $2.6 \%$.

\section{Statistical analysis}

Plasma cortisol levels in the F2 families following confinement were subjected to ANOVA (Genstat 5; Lawes Agricultural Trust) and significant differences between families within lines and between lines were determined using the estimated standard error of the differences between means derived from that analysis. The cortisol data were log-transformed prior to analysis because means and variances were found to be interdependent. Weights, lengths, and plasma cortisol levels in the paired fish were compared using a paired t-test. The relative numbers of HR and LR fish that were identified as dominant were compared using a chi-square test. 


\section{RESULTS}

\section{The effects of confinement on plasma cortisol levels in the F2 families}

The mean plasma cortisol level determined for each family following a $1 \mathrm{~h}$ period of confinement is presented in Fig. 1a. There was considerable between-family variation in the plasma cortisol response to confinement within the HR and LR groups. The range of responsiveness was greater among HR families $\left(148 \pm 18 \mathrm{ng} \mathrm{ml}^{-1}\right.$ to $43 \pm 9$ $\left.\mathrm{ng} \mathrm{ml}^{-1}\right)$ than among LR families $\left(52 \pm 6 \mathrm{ng} \mathrm{ml}^{-1}\right.$ to $\left.31 \pm 3 \mathrm{ng} \mathrm{ml}^{-1}\right)$ and there was no significant difference between the responses of the four lower HR and three higher LR families (Fig. 1a). Overall, mean post-confinement plasma cortisol levels were significantly higher in HR fish $\left(P<0.001 ; 87.5 \pm 4.3 \mathrm{ng} \mathrm{ml}^{-1}\right)$ and US fish $(\mathrm{P}<0.05$; $\left.63.3 \pm 5.3 \mathrm{ng} \mathrm{ml}^{-1}\right)$ than LR fish $\left(39.7 \pm 1.5 \mathrm{ng} \mathrm{ml}^{-1} ;\right.$ Fig. 1b). There was no significant difference between the HR and US groups. There was no significant correlation between fish size and post-stress cortisol levels within any group (HR: $r^{2}=0.0004, P$ $=0.8 ;$ LR: $r^{2}=0.02, P=0.09 ;$ US: $\left.r^{2}=0.04, P=0.26\right)$.

In order to provide an estimate of heritability for the trait, the mean plasma cortisol levels for the F2 progeny groups after confinement were plotted against the mean plasma cortisol response of the corresponding parent fish following confinement. The regression of mid-parent $[($ male + female $) / 2]$ cortisol response on progeny cortisol response is presented in Fig. 2. The regression was highly significant $(P<0.001 ; \mathrm{y}=$ $0.5601 \mathrm{x}+15.38)$ providing an estimate for $h^{2}$ of 0.6 . Male and female parent-progeny regressions provided estimates for $h^{2}$ of 0.73 and 0.44 respectively. 


\section{Testing of relative aggression among $F 2 \mathrm{HR}$ and $\mathrm{LR}$ fish}

Pairing and acclimation: Paired HR and LR fish were size-matched for length only but there was no significant difference between the weights of the paired individuals $(P=0.29 ;$ mean $\%$ difference between paired individuals: $1.71 \pm 1.5 \%, \mathrm{n}=47)$ and the absence of a systematic bias in either direction was demonstrated by regressions of body weight and fork length for the paired fish (weight: $r^{2}=0.95, \mathrm{~b}=0.997$; length: $\left.r^{2}=0.99, \mathrm{~b}=0.990\right)$. Most $(82 \%)$ of the fish were feeding within 2 days of being transferred from holding tanks to the partitioned aquaria. More LR $(n=12)$ than HR $(n=5)$ fish refused food throughout the acclimation period. In all of these pairings the LR fish was subsequently identified as dominant.

Identification of dominants and subordinates within pairs: After removal of the partition on Day 5 agonistic interaction was observed to occur, characterized by the fish circling each other and nipping at the caudal and pectoral fins. Because the aim of this study was primarily to identify the dominant and subordinate individuals no detailed observations were made until $3 \mathrm{~h}$ after the onset of interaction by which time the conflict was resolved and the identity of the dominant and subordinate individuals within each pair was clear. At this time dominant fish were characterized by holding a mid-water position, displaying extensive movement around the tank, nipping and/or chasing the subordinate, and intercepting food. Dominant fish appeared only to chase and nip those subordinates that were moving. Otherwise the dominant individual would occasionally swim toward and "inspect" the subordinate fish. Subordinate fish were typically located on the base of the aquarium, usually immediately adjacent to the aquarium wall, exhibited little swimming activity and directed no aggressive acts towards the dominant individual. In some cases the subordinate fish intercepted food 
but more commonly remained immobile when food was introduced into the tank. These observations are consistent with previous studies on the behavior of subordinate and dominant rainbow trout (Keenleyside and Yamamoto, 1962; Øverli et al., 1999). The scoring of two observers was unanimous with regard to the identity of the dominant and subordinate fish within each tank and mean scores for dominant and subordinate fish were $8.5 \pm 0.4$ and $4.6 \pm 0.2$ respectively. In one pair only, neither fish was identifiable as overtly dominant or subordinate and these fish were eliminated from the analysis.

Somatic data and plasma cortisol levels for dominant and subordinate fish: There was no significant difference in either weight or fork length between fish subsequently identified as dominant and subordinate either on introduction into the aquaria or at time of blood sampling (Fig. 3a). However, plasma cortisol levels were significantly higher $(P<0.001)$ in those fish identified as subordinate on behavioral indices than those identified as dominant (Fig. 3b) at the time of sampling (subordinate: range 1.7 $-435 \mathrm{ng} \mathrm{ml}^{-1}$, median $22.1 \mathrm{ng} \mathrm{ml}^{-1}$; dominant: range $0.8-33.3 \mathrm{ng} \mathrm{ml}^{-1}$, median $4.6 \mathrm{ng}$ $\mathrm{ml}^{-1}$ ). It was not possible to obtain blood samples from the tested fish prior to removal of the partitions but in the HR and LR fish transferred to the aquaria and allowed to acclimate without removal of the partitions no significant difference in plasma cortisol levels was found between the groups (HR: $1.5 \pm 0.4$; LR: $0.7 \pm 0.5 \mathrm{ng}$ $\mathrm{ml}^{-1} ; P=0.29, \mathrm{n}=12$ ). There was no significant difference between plasma cortisol levels in LR fish from this group and LR fish post-testing $\left(8.4 \pm 1.4 \mathrm{ng} \mathrm{ml}^{-1} ; P=0.06\right)$ whereas levels in the tested HR fish were significantly higher than those in the untested group $\left(62.9 \pm 14.5 \mathrm{ng} \mathrm{ml}^{-1} ; P<0.001\right)$. 
The influence of selection for stress responsiveness on behavior during paired encounters: There was a highly significant $(P<0.001)$ difference in the distribution of fish identified as dominant and subordinate between the two stress selection lines. Of the 46 paired contests in which dominant and subordinate fish could be clearly identified, in 43 tests the dominant fish originated within the LR line. In only 3 pairs were HR fish identified as dominant (Fig. 3c).

\section{DISCUSSION}

Rainbow trout selected for low responsiveness to a stressor (LR) grew better than trout selected for high responsiveness to a stressor (HR) when both lines were reared together, a difference not evident when the lines were reared separately. The aim of this study was to determine whether behavioral differences contributed to the better growth of the LR fish. In order to address this question, two lines of rainbow trout selected for divergent plasma cortisol responsiveness to confinement were derived from an existing F1 population, itself the result of selection applied to the F0 generation. Among the F2 fish the divergence of cortisol responsiveness to a confinement stressor, which was evident in the F1 high- and low-responding parents, was maintained. The heritability of this trait, derived from a mid-parent versus progeny regression, was high $\left(h^{2}=0.6\right)$ and consistent with that reported in previous studies ( $h^{2}=0.4$ - 0.6; Fevolden et al., 1999; Pottinger and Carrick, 1999b).

The most aggressive or competitive individuals within a population of salmonid fish compete most successfully for food (Adams et al., 1998) and social dominance/subordination has been extensively studied in salmonid fish because of the 
importance of these attributes to individual performance (Metcalfe, 1989, 1998; Petersson et al., 1999; Ryer and Olla, 1996). The territoriality of juvenile rainbow trout (Hutchison and Iwata, 1997; Keenleyside and Yamamoto, 1962; Taylor, 1990) results in the rapid establishment of a dominant-subordinate relationship when two individuals are confined within a limiting arena (Jönsson, Johnsson and Björnsson, 1998; Øverli et al., 1999; Winberg and Lepage, 1998). The tendency of individuals of the HR and LR lines to establish dominance or become subordinate when paired with an individual from the opposing line was therefore evaluated by observing the outcome of contests for social dominance between paired HR and LR fish.

In the present study, the test fish were introduced into partitioned aquaria 4 days in advance of the contest, allowing time for acclimation to the unfamiliar environment. Plasma cortisol levels in fish allowed to acclimate, but without removal of the partition $\left(<2 \mathrm{ng} \mathrm{ml}^{-1}\right)$ were typical of unstressed rainbow trout (Pottinger and Moran, 1993), and most fish commenced feeding within $24 \mathrm{~h}$ of introduction into the test aquaria suggesting that the transfer procedure and novel environment did not constitute a prolonged stressor. Both relative size (where differences between individuals are substantial; Cutts, Metcalfe and Taylor, 1999) and prior residency (Huntingford and de Leaniz, 1997; Johnsson, Nobbelin and Bohlin, 1999) are important factors in determining the outcome of competitive interactions in salmonid fish, therefore paired fish were size-matched and contests were conducted in an arena comprising the combined "home" compartments of both fish. Fish were not handled following initial transfer to the test tanks and the only potentially stressful stimulus that was imposed prior to the contest was removal of the partition, an event experienced simultaneously by both fish. 
Following removal of the dividing partition, agonistic interaction was observed to occur between the paired fish. Within $3 \mathrm{~h}$ this had resolved into a clearly identifiable dominant and subordinate in all but one of the trials. The behavioral correlates of dominance status were consistent with those previously reported for rainbow trout (Jönsson et al., 1998; Øverli et al., 1999; Winberg and Lepage, 1998) with dominant individuals actively swimming in mid-water, nipping and/or chasing the subordinate, while subordinate fish exhibited little activity, remaining on the base of the aquarium adjacent to a wall, and directing no aggressive activity towards the dominant fish. Food was normally intercepted by the dominant individual and attempts to do so by the subordinate individual resulted in chasing by the dominant. The identification of dominant and subordinate fish in each pair was confirmed by the measurement of plasma cortisol levels in blood samples collected following the observation period. In the present study, mean plasma cortisol levels in fish identified as dominant were typical of levels observed in unstressed rainbow trout while plasma cortisol levels in the subordinate fish were typical of the range of values observed in stressed rainbow trout (Pottinger and Moran, 1994). It is well established that subordinate fish display elevated blood cortisol levels relative to dominant fish (Balm, Pepels, Helfrich, Hovens and Bonga, 1994; Overli et al., 1999; Pottinger and Pickering, 1992; Sloman, Gilmour, Metcalfe and Taylor, 2000; Winberg and Lepage, 1998). This is unsurprising given that subordinate status is considered to represent a severe chronic stressor in most vertebrates (Blanchard, Hebert, Sakai, McKittrick, Henrie, Yudko, McEwen and Blanchard, 1998).

In 43 contests the fish from the LR line was identified as dominant while fish from the 
HR line were dominant in only 3 contests. This polarization of behavior suggests that selection has either increased aggressiveness in the LR line or increased submissiveness in the HR line or has had a combination of these effects on the two lines. Evidently, selection on the basis of the magnitude of cortisol elevation to a stressor has co-selected for pronounced differences in behavior. However, it is unclear whether (i) the behavioral difference is functionally linked to the difference in plasma cortisol elevation which is observed during stress in the two lines; (ii) the behavioral difference is linked to physiological or neuroendocrine elements of the stress response which simultaneously influences both endocrine and behavioral attributes; (iii) the behavioral difference is co-selected with stress responsiveness but is neither directly or indirectly linked to the stress response.

There appeared to be some overlap in the magnitude of the cortisol response to confinement among the "lower-responding" HR families and the "higher-responding" LR families (see Fig. 1a). However, fish from the families with overlapping means displayed the behavioral attributes typical of each line as a whole. For example, fish from Family 11, which displayed the lowest mean response to confinement among the HR families, were paired with LR fish from Families 16, 4 and 27 (twice) all of which families displayed similar or lower mean cortisol responses to confinement. Yet in each case the LR individual was clearly dominant. Although this observation to some extent undermines a direct role of cortisol, the possibility cannot be ruled out.

We have no evidence of systematic differences in plasma cortisol levels in unstressed fish from the HR and LR lines. Therefore, if the behavioral difference between the two lines is directly related to differences in circulating levels of cortisol then it is 
presumably the effects of elevated cortisol levels during the initiation of agonistic interaction between the fish that is of importance. Rapid effects of corticosterone on behavior have been demonstrated in newts (Taricha granulosa) mediated by direct effects of the steroid on neuronal function (Rose and Moore, 1999). We are aware of only one study that provides any evidence for direct behavioral effects of cortisol in fish. Administration of cortisol by immersion to the cichlid Aequidens pulcher resulted in an increase of submissiveness (Munro and Pitcher, 1985). In rainbow trout chronic cortisol elevation achieved by implantation was suggested to have adverse effects on competitive ability (Gregory and Wood, 1999) but this was apparently mediated via appetite suppression, a mechanism which cannot be evoked to account for the results of the present study. The evidence for corticosteroid effects on behavior in other vertebrates is contradictory. In humans, low salivary cortisol has been associated with persistent aggression (McBurnett, Lahey, Rathouz and Loeber, 2000) while in domestic pigs and the blue-footed booby (Sual nebouxii) elevated cortisol and corticosterone have been suggested to facilitate submissive behavior during aggressive interactions (Fernandez, Meuniersalaun and Mormede, 1994; de la Mora, Drummond and Wingfield, 1996) and similarly, administration of corticosterone to the blotched lizard (Uta stansburiana) reportedly reduces aggression (De Nardo and Licht, 1993). However, in contrast to these reports, which indicate a reasonable consistency in the effects of corticosteroids on behavior, no correlation between aggressiveness and plasma corticosterone responsiveness to stressors was reported for rats (Sgoifo, de Boer, Haller and Koolhaas, 1996) and the administration of corticosterone to rats had variable behavioral effects which were dependent on context and experience (Haller, Albert and Makara, 1997). Cortisol actually increased aggression in paired golden hamsters (Mesocricetus auratus; Hayden-Hixson and 
Ferris, 1991) while chronic elevation of blood corticosterone had no effects on aggressive behavior in the tree sparrow (Spizella arborea; Astheimer, Buttemer and Wingfield, 2000). Further studies on the F2 lines of HR and LR rainbow trout may be helpful in resolving the precise behavioral role of cortisol in the rainbow trout.

There is more substantive evidence in fish for a link between the brain serotonergic system, the stress response, and behavior than is available for direct effects of corticosteroids on behavior. Stress increases serotonergic activity in the brain of Arctic charr (Salvelinus alpinus; Winberg, Nilsson and Olsen, 1992) and in rainbow trout administration of a serotonin receptor agonist induces a dose-dependent elevation of plasma cortisol (Winberg, Nilsson, Hylland, Söderstöm and Nilsson, 1997). Elevated levels of serotonergic activity in the brains of subordinate fish are believed to contribute to the behavioral inhibition seen in these individuals (see Øverli et al., 1999 for discussion). Recently it has been shown that exogenous corticosterone increased brain serotonergic activity in the lizard Anolis carolinensis within a time frame that was consistent with possible behavioral effects (Summers, Larson, Ronan, Hofmann, Emerson and Renner, 2000). Collectively these observations indicate the existence of reciprocal relationships between the brain and endocrine system by which individual cortisol levels during stress might be linked to the outcome of agonistic interactions.

In conclusion, fish selected for low stress-responsiveness in terms of cortisol elevation following a period of confinement, are overall more successful in establishing dominance than fish selected for high-responsiveness, when individuals from the two lines are paired on neutral territory. The mechanistic basis for the apparent co- 
selection of polarized behaviors together with stress responsiveness is unclear but both the direct effects of cortisol and the involvement of the brain serotonergic system require further investigation. The HR and LR lines of rainbow trout divergent for stress responsiveness appear to offer a useful model for further investigation of the links between the endocrine system, brain and behavior in fish.

\section{ACKNOWLEDGEMENTS}

This study was carried out with financial support from the Commission of the European Communities, Agriculture and Fisheries (FAIR) specific RTD programme CT95-152 "Selective breeding for stress tolerance in aquacultured fish" and from the Natural Environment Research Council of the UK. The authors thank Dr Øyvind Øverli (Uppsala University) for helpful comments on the manuscript and Mrs M. A. Hurley $(\mathrm{CEH})$ for advice on statistical analysis.

\section{REFERENCES}

Adams, C. E., Huntingford, F. A., Turnbull, J. F. and Beattie, C. (1998). Alternative competitive strategies and the cost of food acquisition in juvenile Atlantic salmon (Salmo salar). Aquaculture 167, 17-26.

Astheimer, L. B., Buttemer, W. A. and Wingfield, J. C. (2000). Corticosterone treatment has no effect on reproductive hormones or aggressive behaviour in free-living male tree sparrows, Spizella arborea. Horm. Behav. 37, 31-39. 
Balm, P. H. M., Pepels, P., Helfrich, S., Hovens, M. L. M. and Bonga, S. E. W. (1994). Adrenocorticotropic hormone in relation to interrenal function during stress in tilapia (Oreochromis mossambicus). Gen. Comp. Endocrinol. 96, $347-360$.

Barton, B. A. (1997). Stress in finfish: past, present and future - a historical perspective. In G. K. Iwama, A. D. Pickering, J. P. Sumpter, and C. B. Schreck, (Eds.), Fish Stress and Health in Aquaculture, pp.1-33. Cambridge University Press, Cambridge.

Blanchard, R. J., Hebert, M., Sakai, R. R., McKittrick, C., Henrie, A., Yudko, E., McEwen, B. S. and Blanchard, D. C. (1998). Chronic social stress: Changes in behavioral and physiological indices of emotion. Aggressive Behavior 24, 307321.

Cutts, C. J., Metcalfe, N. B., and Taylor, A. C. (1999). Competitive asymmetries in territorial juvenile Atlantic salmon, Salmo salar. Oikos 86, 479-486.

De la Mora, A. N., Drummond, H. and Wingfield, J. C. (1996). Hormonal correlates of dominance and starvation-induced aggression in chicks of the blue-footed booby. Ethology 102, 748-761.

De Nardo, D. F. and Licht, P. (1993). Effects of corticosterone on social behavior of male lizards. Horm. Behav. 27, 184-99. 
Fernandez, X., Meuniersalaun, M. C. and Mormede, P. (1994). Agonistic behavior, plasma stress hormones, and metabolites in response to dyadic encounters in domestic pigs - interrelationships and effect of dominance status. Physiol. Behav. 56, 841-847.

Fevolden, S.-E., Rped, K. H., Fjalestad, K. T., and Stien, J. (1999). Post-stress levels of lysozyme and cortisol in adult rainbow trout (Oncorhynchus mykiss); heritabilities and genetic correlations. J. Fish Biol. 54, 900-910.

Gregory, T. R. and Wood, C. M. (1999). The effects of chronic plasma cortisol elevation on the feeding behaviour, growth, competitive ability, and swimming performance of juvenile rainbow trout. Physiol. Biochem. Zool. 72, 286-295.

Haller, J., Albert, I. and Makara, G. B. (1997). Acute behavioural effects of corticosterone lack specificity but show marked context-dependency. $J$. Neuroendocrinol. 9, 515-518.

Hayden_Hixson, D. M. and Ferris, C. F. (1991). Steroid-specific regulation of agonistic responding in the anterior hypothalamus of male hamsters. Physiol. Behav. 50, 793-799.

Huntingford, F. A. and de Leaniz, C. G. (1997). Social dominance, prior residence and the acquisition of profitable feeding sites in juvenile Atlantic salmon. $J$. Fish Biol. 51, 1009-1014. 
Hutchison, M. J. and Iwata, M. (1997). A comparative analysis of aggression in migratory and non-migratory salmonids. Environ. Biol. Fishes 50, 209-215.

Johnsson, J. I., Nobbelin, F., and Bohlin, T. (1999). Territorial competition among wild brown trout fry: effects of ownership and body size. J. Fish Biol. 54, 469472.

Jönsson, E., Johnsson, J. I. and Björnsson, B. T. (1998). Growth hormone increases aggressive behaviour in juvenile rainbow trout. Horm. Behav. 33, 9-15.

Keenleyside, M. H. A. and Yamamoto, F. T. (1962). Territorial behaviour of juvenile Atlantic salmon (Salmo salar L.). Behaviour 19, 139-169.

McBurnett, K., Lahey, B. B., Rathouz, P. J. and Loeber, R. (2000). Low salivary cortisol and persistent aggression in boys referred for disruptive behaviour. Arch. Gen. Psych. 57, 38-43.

Metcalfe, N. B. (1989). Differential response to a competitor by Atlantic salmon adopting alternative life-history strategies. Proc. Roy. Soc. Lond. B 236, 21-27.

Metcalfe, N. B. (1998). The interaction between behaviour and physiology in determining life history patterns in Atlantic salmon (Salmo salar). Can. J. Fish. Aquat. Sci. 55 (Suppl. 1), 93-103. 
Munro, A. D. and Pitcher, T. J. (1985). Steroid hormones and agonistic behaviour in a cichlid teleost, Aequidens pulcher. Horm. Behav. 19, 353-371.

Øverli, Ø., Harris, C. A. and Winberg, S. (1999). Short-term effects of fights for social dominance and the establishment of dominant-subordinate relationships on brain monoamines and cortisol in rainbow trout. Brain Behav. Evol. 54, 263-275.

Petersson, E., Jarvi, T., Olsen, H., Mayer, I. and Hedenskog, M. (1999). Male-male competition and female choice in brown trout. Anim. Behav. 57, 777-783

Pottinger, T. G. and Carrick, T. R. (1999a). A comparison of plasma glucose and plasma cortisol as selection markers for high and low stress-responsiveness in female rainbow trout. Aquaculture 175, 351-363.

Pottinger, T. G. and Carrick, T. R. (1999b). Modification of the plasma cortisol response to stress in rainbow trout by selective breeding. Gen. Comp. Endocrinol. 116, 122-132.

Pottinger, T. G. and Moran, T. A. (1993). Differences in plasma cortisol and cortisone dynamics during stress in two strains of rainbow trout (Oncorhynchus mykiss). J. Fish Biol. 43, 121-130. 
Pottinger, T. G. and Pickering, A. D. (1992). The influence of social interaction on the acclimation of rainbow trout, Oncorhynchus mykiss (Walbaum) to chronic stress. J. Fish Biol. 41, 435-447.

Pottinger, T. G., Pickering, A. D. and Hurley, M. A. (1992). Consistency in the stress response of individuals of two strains of rainbow trout, Oncorhynchus mykiss. Aquaculture 103, 275-289.

Rose, J. D. and Moore, F. L. (1999). A neurobehavioural model for rapid actions of corticosterone on sensorimotor integration. Steroids 64, 92-99.

Ryer, C. H. and Olla, B. L. (1996). Growth depensation and aggression in laboratory reared coho salmon: the effect of food distribution and ration size. J. Fish Biol. 48, 686-694.

Sgoifo, A., de Boer, S. F., Haller, J. and Koolhaas, J. M. (1996). Individual differences in plasma catecholamine and corticosterone stress responses of wild-type rats: relationship with aggression. Physiol. Behav. 60, 1403-1407.

Sloman, K. A., Gilmour, K. M., Metcalfe, N. B. and Taylor, A. C. (2000). Does socially induced stress in rainbow trout cause chloride cell proliferation? $J$. Fish Biol. 56, 725-738. 
Summers, C. H., Larson, E. T., Ronan, P. J., Hofmann, P. M., Emerson, A. J. and Renner, K. J. (2000). Serotonergic responses to corticosterone and testosterone in the limbic system. Gen. Comp. Endocrinol. 117, 151-159.

Taylor, E. B. (1990). Phenotypic correlates of life-history variation in juvenile Chinook salmon Oncorhynchus tshawytscha. J. Anim. Ecol. 59, 455-468.

Winberg, S. and Lepage, O. (1998). Elevation of brain 5-HT activity, POMC expression, and plasma cortisol in socially subordinate rainbow trout. Am. J. Physiol. 274, R645-R654.

Winberg, S., Nilsson G. E. and Olsen, K. H. (1992). The effect of stress and starvation on brain serotonin utilization in arctic charr (Salvelinus alpinus). J. Exp. Biol. 165, 229-239.

Winberg, S., Nilsson, A., Hylland, P., Söderstöm, V. and Nilsson, G. (1997). Serotonin as a regulator of hypothalamic-pituitary-interrenal activity in teleost fish. Neurosci. Lett. 230, 1-4. 


\section{FIGURE LEGENDS}

Figure 1. (a) Mean plasma cortisol levels after a $1 \mathrm{~h}$ period of confinement in F2 families of rainbow trout, derived from single male-female crosses of F1 fish selected on the magnitude of their plasma cortisol response to a confinement stressor. HR: high-responding; LR: low-responding; US: unselected. Mean plasma cortisol levels for HR families were significantly different from LR families $(P<0.001)$ except where indicated by A. $n=10$ for each mean + SEM. (b) Mean plasma cortisol levels for each selection line. Asterisks denote significant differences from the LR line: $* * * P<0.001$, $* P<0.05, \mathrm{n}=11,11,3$ families respectively (10 replicate fish per family $)+$ SEM.

Figure 2. A regression of the mean plasma cortisol response to confinement in each F2 progeny group against the mean $[($ male + female $) / 2]$ response of the corresponding F1 parents. HR $\forall$, LR !. The dotted lines indicate the 95\% confidence limits and prediction limits; $\mathrm{y}=0.5601 \mathrm{x}+15.38 ; P<0.001$.

Figure 3. (a) Mean body weights and fork lengths, for fish identified as dominant and subordinate, before transfer to the test aquaria (mean + SEM, $n=47$ ). (b) Mean plasma cortisol levels in fish identified as dominant or subordinate during the paired contests. (mean + SEM, $n=46$ ). (c) The number of HR and LR fish identified as either dominant or subordinate during the paired contests. HR subordinates $>$ LR subordinates, $P<0.001$, chi-square test. 
Figure 1.
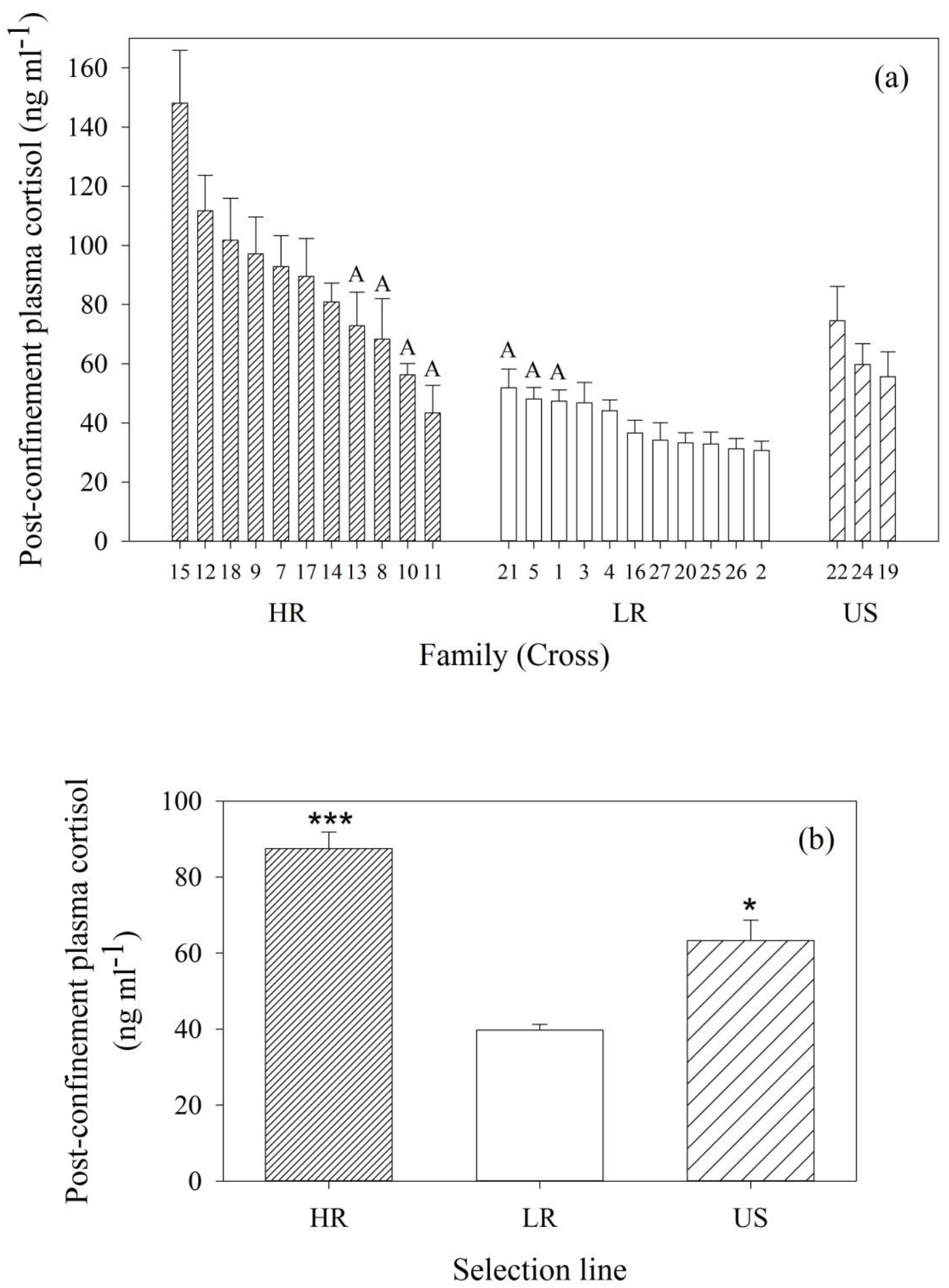
Figure 2.

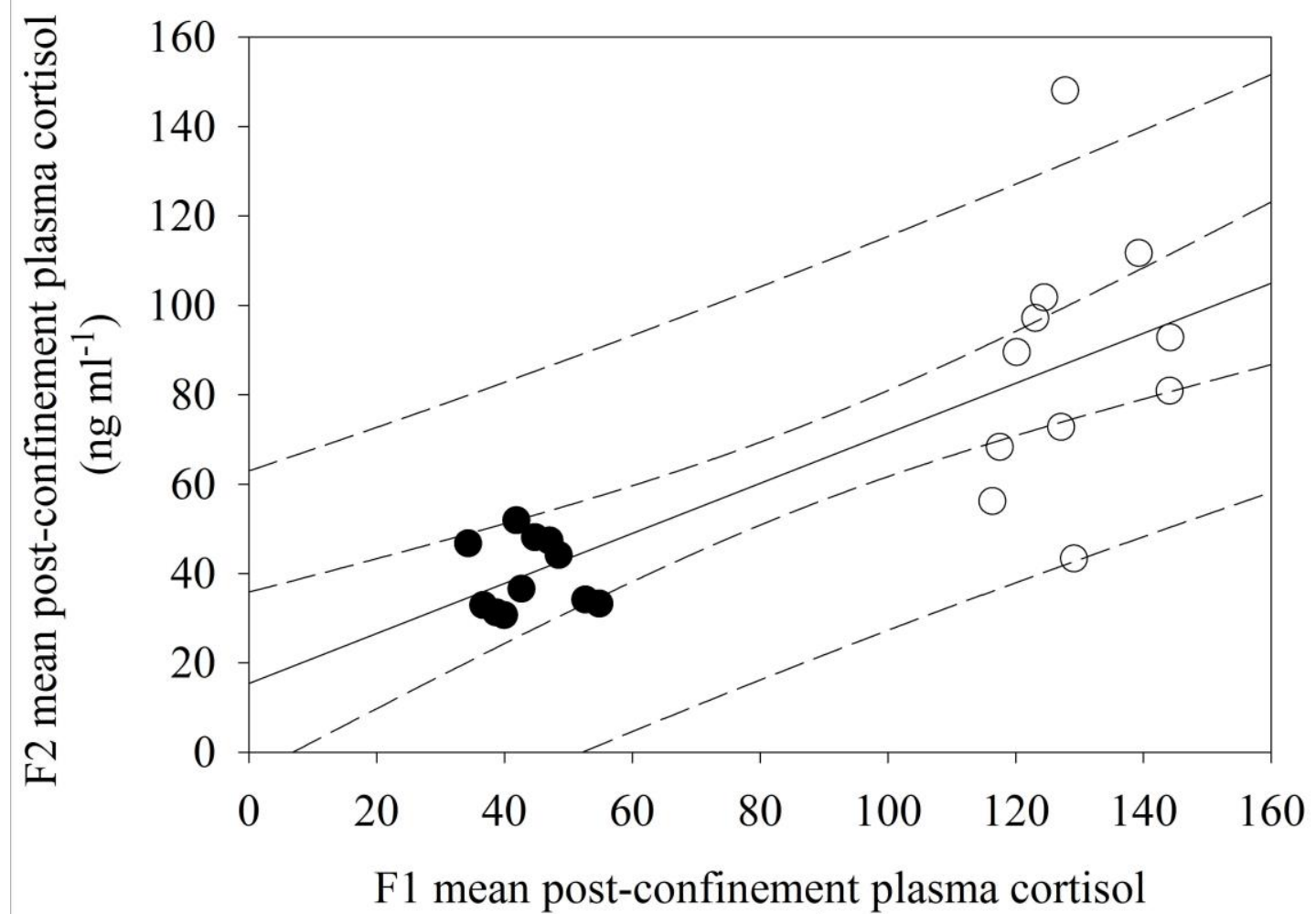

(ng ml-1) 
Figure 3.
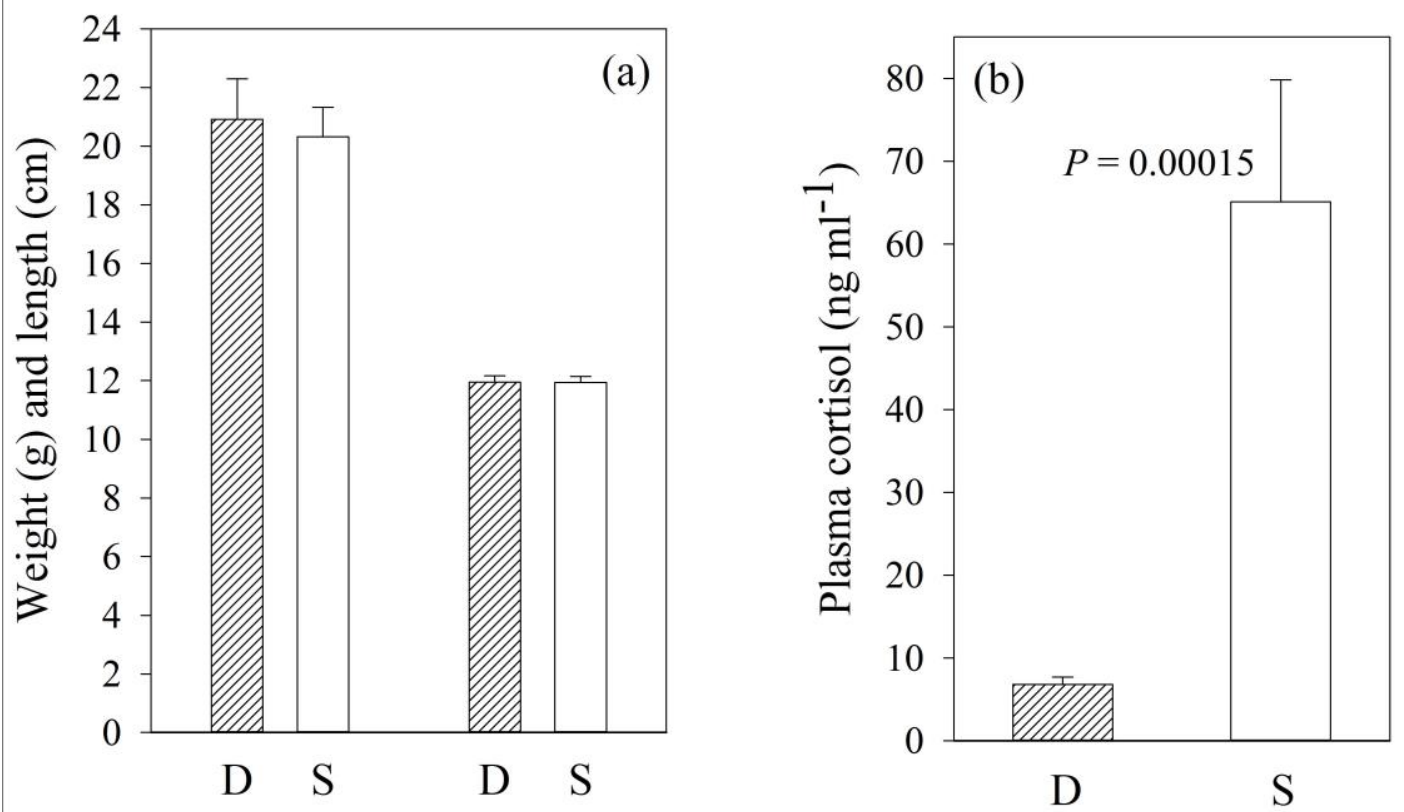

Weight Length

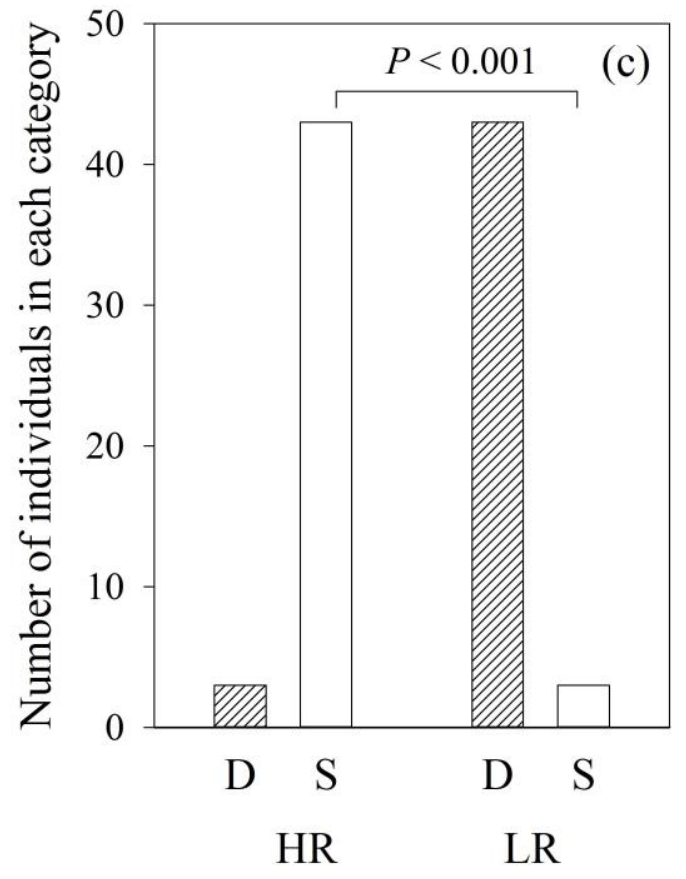

